\title{
Climate Aridity under Changing Conditions and Implications for the Agricultural Sector: Italy as a Case Study
}

\author{
Luca Salvati, ${ }^{1}$ Marco Zitti, ${ }^{2}$ Rosanna Di Bartolomei, ${ }^{1}$ and Luigi Perini ${ }^{3}$ \\ ${ }^{1}$ Consiglio per la Ricerca e la Sperimentazione in Agricoltura, \\ Centro di Ricerca per lo Studio delle Relazioni tra Pianta e Suolo (CRA-RPS), Via della Navicella 2-4, 00184 Roma, Italy \\ ${ }^{2}$ Metodi e Modelli per l'Economia, il Territorio e la Finanza (MEMOTEF), Università di Roma "Sapienza", \\ Via del Castro Laurenziano 9, 00161 Roma, Italy \\ ${ }^{3}$ Unità di Ricerca per la Climatologia e la Meteorologia Applicate all'Agricoltura (CRA-CMA), \\ Consiglio per la Ricerca e la Sperimentazione in Agricoltura, Via del Caravita 7a, 00186 Roma, Italy
}

Correspondence should be addressed to Rosanna Di Bartolomei; rdibartolomei@gmail.com

Received 30 August 2012; Accepted 31 October 2012

Academic Editor: Tonny J. Oyana

Copyright (C) 2013 Luca Salvati et al. This is an open access article distributed under the Creative Commons Attribution License, which permits unrestricted use, distribution, and reproduction in any medium, provided the original work is properly cited.

A comprehensive diachronic analysis (1951-2010) of precipitation and temperature regimes has been carried out at the national and regional scale in Italy to investigate the impact of climate aridity on the agricultural system. Trends in climate aridity have been also analysed using UNEP aridity index which is the ratio between rainfall and potential evapotranspiration on a yearly basis. During the examined time period, and particularly in the most recent years, a gradual reduction in rainfall and growing temperatures have been observed which have further widened the gap between precipitation amounts and water demand in agriculture.

\section{Introduction}

In recent years, Italy has been experiencing growing water scarcity that can be mainly related to climate variations and poor soil and water management [1-4]. Scholars, although still debating about the causes and possible remedies, recognize that a gradual warming process is occurring at wider scales also altering, at local level, the rainfall regime [5-7]. Bates et al. [8] indicates that observed warming over several decades has been linked to large-scale hydrological changes (i.e., increasing atmospheric water vapour content, changing precipitation patterns, reduced snow cover and widespread ice melting, changes in soil moisture and runoff).

Mediterranean Basin is particularly exposed to the impacts of climate change. Particularly, the gradual heating along coasts in recent years, especially in summer, resulted in an increase of the average temperatures in coastal waters up to 3 degrees, producing phenomena of the mucilage and tropicalization of flora and fauna. In these regions, also, climate projections outline a decreased water availability due to less abundant, irregularly distributed, and intense rainfall throughout the year compared to the past $[3,9,10]$. At country scale, Italy, due to the particular geographical form, is an example of spatial heterogeneity in climate regimes shaping also climate variations at a local level. As a matter of fact, changes in temperature and precipitation regimes are not evenly distributed on the country, but differ from place to place depending on both the structural component (climate) of variability associated with the atmospheric system and on the random component (weather).

One of the most important consequences of climate change for the Mediterranean environment is the increasing frequency of drought episodes and the growing impact of climate aridity on agroforest ecosystems $[8,11,12]$. Although hard to distinguish considering their effects, the conceptual difference between aridity and drought is equivalent to that between climate and weather [13]. In the case of aridity, the lack of rainfall depends on the local climate and represents a permanent or seasonal condition. On the contrary, drought is a transitory phenomenon related to the meteorological 
variability and, as such, it can strike everywhere and at any time with levels of intensity and persistence which cannot be determined a priori [14].

Aridity and drought, however, represent two sides of the same coin: along with the long-term trends triggered by climate change there has been in Italy a tight recurrence of drought episodes that have recently affected in an undifferentiated manner areas previously not prone to such phenomena, such as Northern Italy, as well as others where the preexisting water shortage has been exacerbated by the increased climate aggressiveness as in central and southern Italy [1517].

The analysis of annual and seasonal rainfall for the period 1951-2002 revealed that in Italy there has been an increase of the surface area experiencing drier rainfall regimes. Perini et al. [18] shows that the most relevant cases are recorded in province of Foggia, where the portion of land area receiving less than $600 \mathrm{~mm}$ annual rainfall increased from 15\% to $61 \%$, in the province of Oristano (from $8 \%$ to $76 \%$ ) and Nuoro ( $46 \%$ to $79 \%)$. In other provinces, such as Campobasso, where there has been an increase from $0 \%$ to $21 \%$, the size of the phenomenon is relatively less considerable although a significant trend towards drought conditions has been equally identified, while in the province of Grosseto the portion of land subject to reduced rainfall did not change over time, remaining slightly less than 1\% [19]. Many Italian regions are still characterized by a considerable year by year variability (e.g., Salento, Central and Northern Appennine areas, South-Eastern Sicily, and even Valle D’Aosta), showing a coefficient of variation (CV) between 20 and $30 \%$ of the average annual rainfall [18]. In several regions the rainfall seasonality, typical of the Mediterranean climate, strengthens the effects and impacts of climate change: the recorded autumn-winter rainfall is three times higher than the springsummer one. Along the Tyrrhenian coast, by contrast, spring and summer rainfall is equal to half of the autumn-winter one, while generally in the Northern regions and along the middle Adriatic the distribution of rainfall throughout the year is more evenly spread $[15,20,21]$.

Considering the above-mentioned, structural trends in climate aridity and the increasing frequency in drought episodes, the strengthening of their negative impact on both man and the environment can lead to desertification [22]. That being said, it was necessary to carry out a territorial analysis able to outline the overall national framework in terms of intensity, spatial distribution, and temporal evolution of water shortage caused by aridity also discussing the possible implications in the agricultural sector.

\section{Methods}

A quite common method for quantifying the gap between rainfall contributions and water demand is the Aridity Index (AI) which, in the formulation adopted by United Nations Environment Programme (UNEP), Food and Agriculture Organization (FAO), and United Nations Convention to Combat Desertification (UNCCD), represents a simple but effective scientific investigation tool and an operational
TABLE 1: Classification of aridity index (AI).

\begin{tabular}{lc}
\hline Aridity Index $(\mathrm{AI})$ values & Climate classification \\
\hline $\mathrm{AI}<0.05$ & Hyper-arid \\
$0.05<\mathrm{AI}<0.2$ & Arid \\
$0.2<\mathrm{AI}<0.5$ & Semi-arid \\
$0.5<\mathrm{AI}<0.65$ & Dry sub-humid \\
$0.65<\mathrm{AI}>0.75$ & Humid \\
$\mathrm{AI}>0.75$ & Hyper-humid \\
\hline
\end{tabular}

support to territorial monitoring and classification. The Aridity Index is calculated by dividing the total annual precipitation $(P)$ by the annual potential evapotranspiration (ET0):

$$
\mathrm{AI}=\frac{P}{\mathrm{ET} 0} .
$$

The AI index can be defined as a bioclimatic index, as it takes into account both physical phenomena (precipitation and potential evapotranspiration) and biological processes (plant transpiration). Moreover, such index represents one of the most relevant indicators for studying desertification processes [23-25]. As a rule, AI values below 0.5 define arid or semi-arid areas, while values over 0.65 describe humid and hyper-humid zones as shown in Table 1.

The metereological data to calculate the annual precipitation and potential evapotranspiration values have been gathered from the National Agrometeorological Data Base (BDAN). This database is a computerized archive designed within the National Agricultural Information System (SIAN) of the Ministry of Agriculture food and forestry policies (MiPAAF). BDAN consists of basic observation data deriving from meteorological stations belonging to various National and local monitoring networks, mainly CRA-CMA (formerly UCEA), Air Force, former Hydrographic and Mareographic Service, and several regional agrometeorological services. In addition to elementary data, BDAN includes a number of climate statistics and various agrometeorological data.

In order to meet the fundamental requirements of reliability, territorial coverage, uniformity, completeness, and consistency of the time series, we have chosen to use the daily data series from 1951 to 2010 of Minimum Temperature $(\mathrm{Tn})$, Maximum Temperature (Tx), and Precipitation $(P)$ calculated through a geostatistical technique (Kriging) at the nodes of a square grid of $30 \times 30 \mathrm{Km}$, covering the entire Italian territory [26-28]. Basically, Kriging is an interpolation method to estimate, at all points across a well-defined spatial domain, the unknown value of a given size (in our case temperatures and precipitations) using a weighted average of known values of the same size around the point to be estimated. Tn and Tx values were used to calculate ET0. Indeed, in the specific case of this study, the estimated potential evapotranspiration was obtained using Hargreaves/Samani formula which requires the above daily temperature data [29].

The weather and climatic data used in this work are the complete set of daily values (about 40 million records) of air temperature (minimum and maximum), rainfall, sunshine 


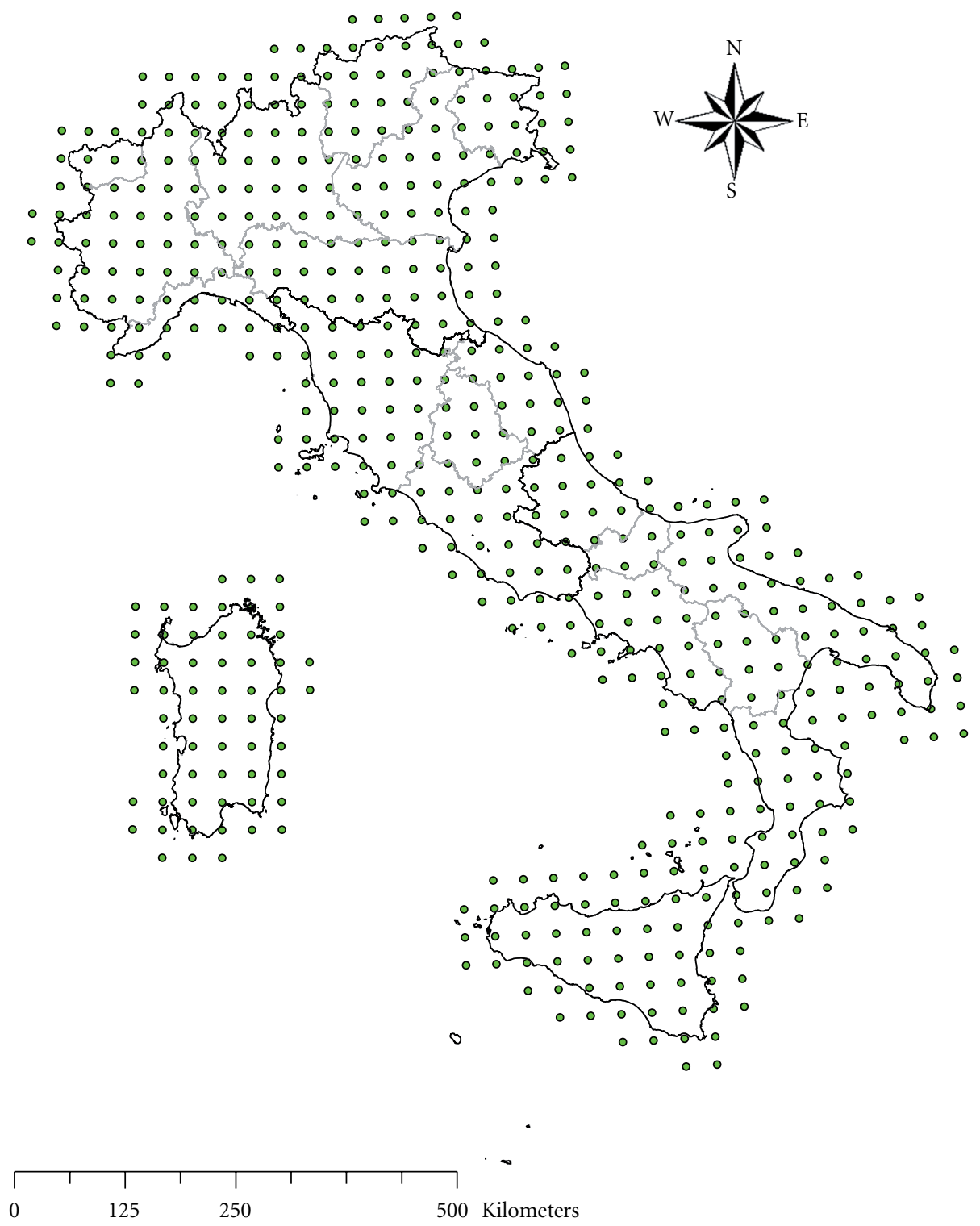

Figure 1: The grid Italy used by CRA-CMA for spatial stochastic meteorological.

duration, relative humidity, and wind speed $(10 \mathrm{~m})$ estimated at 544 points (grid nodes) of the Italian territory (Figure 1) evenly distributed on the basis of a regular pattern derived from about 3000 weather stations belonging at BDAN. Through several computational steps, the daily values of $P$ and ET0 were aggregated up to the annual level and used to calculate the AI obtaining a complete matrix of 32.640 index values (60 years $\times 544$ grid nodes). In order to obtain information also on the spatial distribution of the AI, the resulting data matrix were properly processed using GIS technology (Geographic Information System) after compaction of the temporal dimension obtained by calculating moving averages over a 30-year window [30]. For each grid node, mean AI values relating to the periods 1951-1980 and 1981-2010 were obtained. Such operation, besides compacting the data matrix for an easier information management, has allowed to adequately filter AI interannual variability restoring a more stable spatial characterization of the magnitude. The thematic cartography, being the nodes arranged in a regular grid, has been in turn obtained by means of the Inverse Distance Weighting (IDW) interpolation technique with neutral power (i.e., equal to 1) [31].

\section{Results and Discussion}

Between 1951 and 2010 the national territory showed an overall average AI value equal to 0.90 (Table 2) that indicates an equilibrium of rainfall and potential evapotranspiration. From this view, could be classified as whole countries not vulnerable to the effects of both aridity and drought.

During the investigated time period, however, quite complex and heterogeneous situations occurred, due to both climate variability related to the rainfall regime and 
TABLE 2: Minimum, average, and maximum yearly aridity index (AI) values grouped by italian region for the period 1951-2010. Average values and ranking and percentage variation of the AI have been calculated also for the periods 1951-1980 and 1981-2010. Data source and processing of CRA-CMA.

\begin{tabular}{|c|c|c|c|c|c|c|c|c|}
\hline \multirow{2}{*}{ Region } & \multicolumn{3}{|c|}{$1951-2010$} & \multicolumn{2}{|c|}{$1951-1980$} & \multicolumn{2}{|c|}{$1981-2010$} & \multirow{2}{*}{$\%$ Variation } \\
\hline & Minimum & Average & Maximum & Average & Ranking & Average & Ranking & \\
\hline \multicolumn{9}{|l|}{ Northern } \\
\hline Valle d'Aosta & 0.52 & 1.43 & 3.08 & 1.51 & 19 & 1.34 & 20 & -11.3 \\
\hline Emilia Romagna & 0.54 & 0.89 & 1.47 & 0.96 & 8 & 0.81 & 10 & -15.3 \\
\hline Trentino Alto Adige & 0.73 & 1.32 & 2.39 & 1.43 & 18 & 1.20 & 18 & -16.5 \\
\hline Veneto & 0.65 & 1.08 & 1.73 & 1.18 & 14 & 0.98 & 15 & -17.2 \\
\hline Liguria & 0.48 & 1.07 & 1.81 & 1.19 & 15 & 0.95 & 14 & -20.5 \\
\hline Piedmont & 0.54 & 1.15 & 2.12 & 1.28 & 16 & 1.01 & 17 & -21.3 \\
\hline Lombardy & 0.56 & 1.16 & 2.21 & 1.32 & 17 & 1.00 & 16 & -24.2 \\
\hline Friuli Venezia Giulia & 0.89 & 1.56 & 3.01 & 1.82 & 20 & 1.30 & 19 & -28.6 \\
\hline \multicolumn{9}{|l|}{ Centre } \\
\hline Umbria & 0.53 & 0.92 & 1.45 & 0.99 & 10 & 0.84 & 12 & -15.2 \\
\hline Latium & 0.50 & 0.87 & 1.39 & 0.95 & 7 & 0.80 & 8 & -15.6 \\
\hline Marche & 0.52 & 0.90 & 1.40 & 0.99 & 9 & 0.81 & 9 & -17.9 \\
\hline Tuscany & 0.52 & 0.94 & 1.62 & 1.06 & 13 & 0.82 & 11 & -22.0 \\
\hline \multicolumn{9}{|l|}{ South } \\
\hline Basilicata & 0.45 & 0.73 & 1.08 & 0.78 & 4 & 0.68 & 4 & -13.1 \\
\hline Apulia & 0.34 & 0.60 & 0.98 & 0.64 & 3 & 0.56 & 3 & -13.6 \\
\hline Abruzzo & 0.45 & 0.78 & 1.22 & 0.84 & 5 & 0.71 & 6 & -14.9 \\
\hline Calabria & 0.55 & 0.93 & 1.44 & 1.01 & 12 & 0.84 & 13 & -17.1 \\
\hline Campania & 0.50 & 0.89 & 1.38 & 1.00 & 11 & 0.79 & 7 & -20.6 \\
\hline Molise & 0.48 & 0.79 & 1.25 & 0.89 & 6 & 0.69 & 5 & -22.3 \\
\hline \multicolumn{9}{|l|}{ Islands } \\
\hline Sicily & 0.27 & 0.56 & 0.97 & 0.57 & 1 & 0.55 & 2 & -3.4 \\
\hline Sardinia & 0.29 & 0.55 & 0.96 & 0.62 & 2 & 0.48 & 1 & -22.3 \\
\hline Italy & 0.49 & 0.90 & 1.54 & 0.99 & & 0.81 & & -18.4 \\
\hline
\end{tabular}

temperature pattern, and the peculiarities of the geographical environment of the various areas concerned (regions, [32$34]$ ). With reference to the national aggregation scale, AI values fluctuated between a minimum of 0.49 and a maximum of 1.54, namely between conditions of semiarid and hyperhumid climate (Table 2).

A close examination of the individual regional cases contributes to outlining an even more complex framework of substantially differentiated situations. For example, in the case of Sicily, Sardinia, and Apulia, AI values are among the lowest in the national rankings, owing to mean rainfall below $600 \mathrm{~mm} /$ year and potential evapotranspiration almost twice higher. Indeed, in such regions from 1951 to 2010 the average AI value ranges between 0.55 and 0.60 reaching, in some years, minimum values close to the aridity threshold $(\mathrm{AI}<0.2)$. The northern and part of the central regions as well, show index values close to or higher than 1, thanks to generally more abundant rainfall, such as to counterbalance or exceed what potentially required in terms of evapotranspiration. Also in these regions, however, climate variability entailed a fluctuation of the AI between minimum values of about 0.5 and maximum values even higher than 3 (Friuli Venezia Giulia and Valle d'Aosta).
Table 2 also shows however an element shared by all Italian regions, namely the negative variation intervening between the 30-year periods 1951-1980 and 1981-2010. Indeed, relevant percentage variations emerged from the diachronic comparison: at national level, AI negative variation is over 18 percentage points, while at regional level such variation ranges from a record reduction in Friuli Venezia Giulia $(-28.6 \%)$ to a minimum level in Sicily $(-3.4 \%)$. Data analysis reveals that this phenomenon is mainly due to both rainfall reduction and temperature increase (and therefore potential evapotranspiration) that most recently have heightened the preexisting conditions of aridity and made drought periods longer [35]. This is also confirmed by the fact that the years mainly associated with low AI values have a barycenter in the period 1981-2010, while the years associated with higher values have their center of mass in the period 1951-1980.

The temporal pattern of Aridity Index can be easily inferred from Figure 2, which shows the trend lines by geographical division of the Italian territory (North, Center, South, and Islands). The chart clearly shows that the temporal variability of the examined phenomena also responds to a geographical gradient being much more evident in 


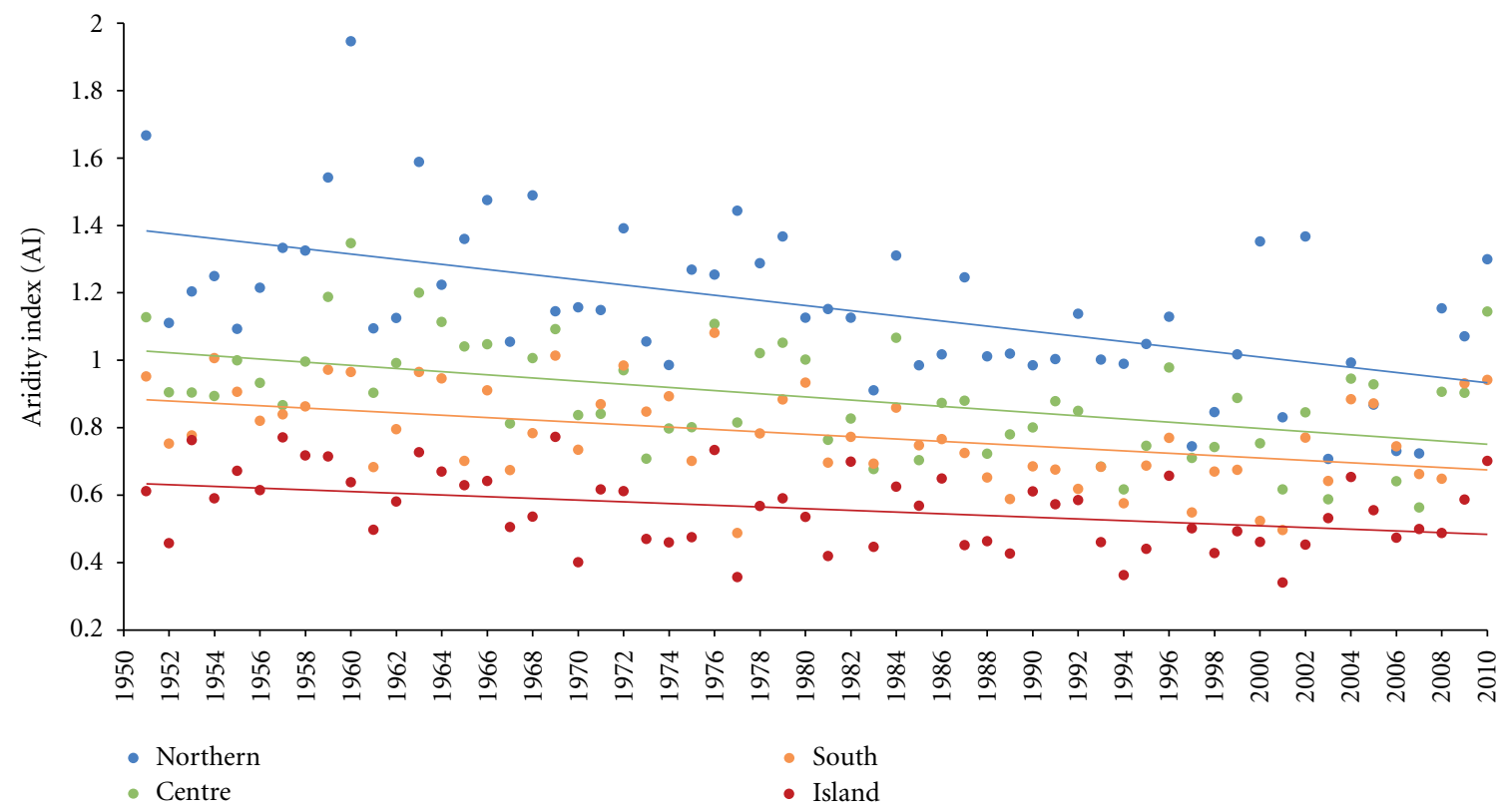

FIgure 2: Trends in the Aridity Index by geographical division in Italy.

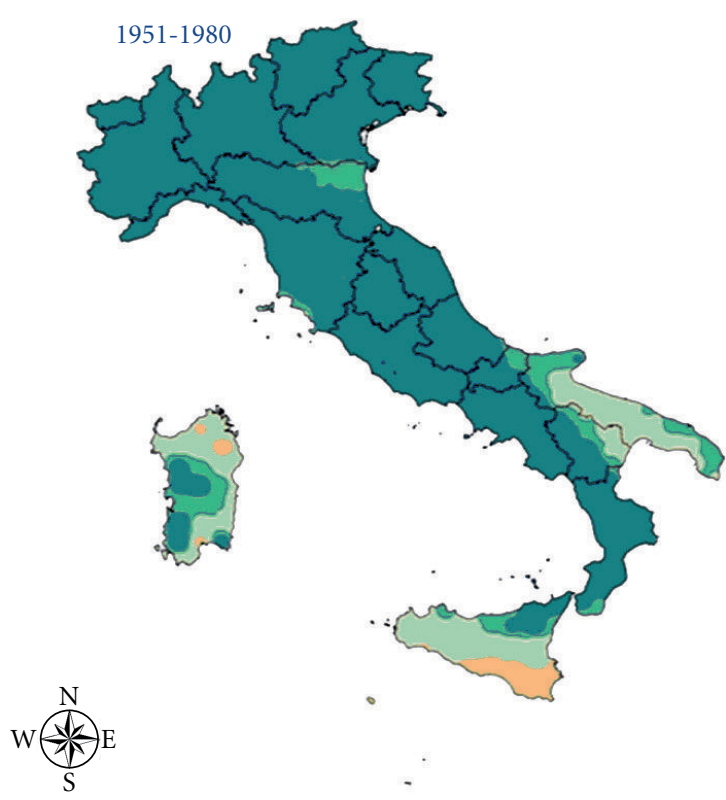

$1981-2010$

Aridity index (AI)
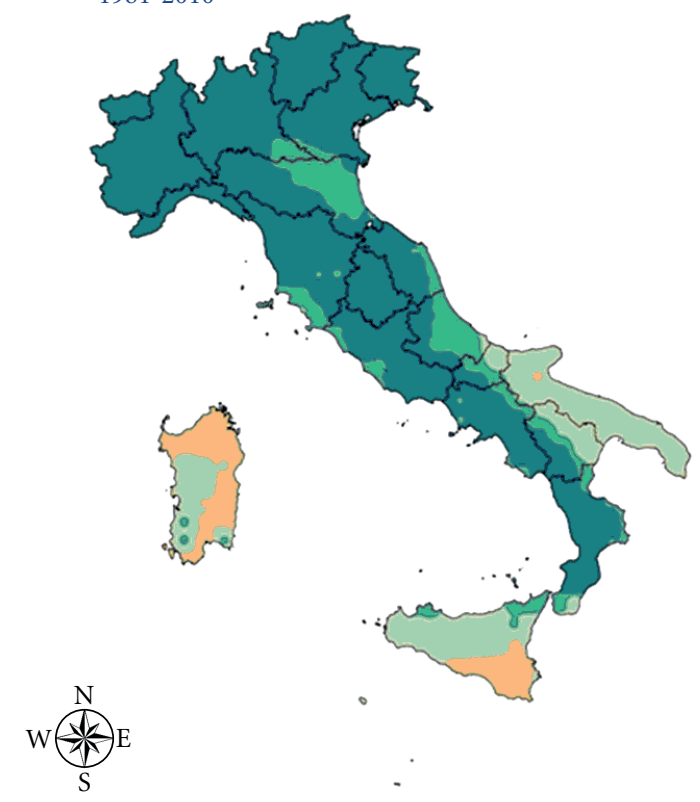

$0-0.03$
$0.03-0.2$
$0.2-0.5$

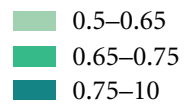

(a)

Aridity index (AI)

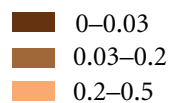

$0.03-0.2$

$0.2-0.5$

FIgURE 3: The spatial distribution of the Aridity Index in Italy by time period. 
the northern regions than in the southern ones. Some of the most significant Italian examples are represented by the cases of Sardinia and Friuli Venezia Giulia [36]. In the second 30-year period (1981-2010), Sardinia, whose initial conditions (between 1951 and 1980) were not so critical $(\mathrm{AI}=0.62 ; P=870 \mathrm{~mm})$, recorded a variation of $\mathrm{AI}$ equal to $-22.3 \%$ which places the region below the threshold discriminating arid areas ( $\mathrm{AI}=0.48)$. It is important to know that rainfall in Sardinia has equally decreased by 42\% $(P=506 \mathrm{~mm})$. In Friuli Venezia Giulia, AI variation totaled $-28.6 /($ from 1.82 to 1.30 ), while rainfall variation $-26.0 \%$ (from $1456 \mathrm{~mm}$ to $1080 \mathrm{~mm}$ ). Although the latter case shows an even more pronounced decrease of the AI and rainfall contributions equal to those of Sardinia (about $370 \mathrm{~mm} /$ year), the climate conditions in the region are still favorable, especially if compared to other regions. A full comparison, from a diachronic and territorial point of view, can be deduced from Figure 3. Both maps show that most of the national territory falls within a range of AI values higher than 0.65 and, consequently, its climate can be defined as "humid" or "hyper-humid" according to the empirical classification associated with the values of the aridity index. Once again, interesting is the critical drying up phenomenon, resulting from worsening climate conditions occurred during 1981-2010 that affected the southern regions and islands.

Additional analysis revealed that winter and autumn are periods of rainfall surplus compared to the potential evapotranspiration demand (rainfall is four or more times higher than potential evapotranspiration). Indeed, such seasons play a crucial role in the restoring the water capacity of the soil. During spring, when the water demand is higher, rainfall is approximately equal to potential evapotranspiration. Exceptions are some regions of southern Italy (especially Apulia, Sardinia, and Sicily), where already in this season the Aridity Index underlines more or less pronounced critical conditions [25].

\section{Conclusions}

The Aridity Index (AI) is a widespread and simple tool that allowed to analyze the magnitude of the aridity and drought phenomena all over the national territory for a reasonable number of years (1951-2010). In addition to the absolute values and relevant climate classifications, the AI has allowed us to verify geographical characteristics and differences as well as the climate variations occurred. Also considering the overall worsening recorded during the last 30 -year period, the most serious aridities phenomena affect only part of the Italian territory (e.g., Sardinia and Sicily) and marginally other southern regions. In these areas, the environmental conditions are more unfavorable and agriculture, grazing, and other human activities affect local environmental conditions. Indeed, the increase in aridity has changed the status of the natural resources that are affected by the production activities, in particular soil, vegetation, and water resources [37]. The data provided in this paper pointed out how, in the last 30 years, Italy was affected by various degrees of water stress mainly due to scarce or badly distributed rainfall throughout the year. The increase of bare soil or cover with sparse vegetation creates an increase of the solar radiation, such that, the more the soil moisture evaporates, the more the ground becomes increasingly drier in a feedback process possibly, accelerating degradation of the Italian lands [38]. In conclusion, considering all the facts above mentioned, it should be kept in mind that agro-ecosystems are the result of the adaptation to specific environmental conditions (climate) and any variation, which could alter the ecological and biocenotic balance, needs to be reoriented in the name of sustainable land management policies and agricultural practices.

\section{References}

[1] M. Brunetti, M. Maugeri, F. Monti, and T. Nanni, "The variability and change of Italian climate in the last 160 years," Nuovo Cimento della Societa Italiana di Fisica C, vol. 29, no. 1, pp. 3-12, 2006.

[2] European Commission, "Mediterranean Water Scarcity and Drought report-technical report on water scarcity and drought management in the Mediterranean and the Water Framework Directive," Tech. Rep. 009, 2007, http://www.emwis. net/topics/WaterScarcity.

[3] C. Carraro, J. Crimi, and A. Sgobbi, La valutazione economica degli impatti dei cambiamenti climatici in Italia e delle relative misure di adattamento, APAT and CMCC, 2007.

[4] A. Massarutto, "Acqua e cambiamenti climatici", Compact n. 03/2011 CIPRA International, http://www.cipra.org/it/cc.alps/ risultati/compacts, 2011.

[5] M. H. I. Dore, "Climate change and changes in global precipitation patterns: what do we know?" Environment International, vol. 31, no. 8, pp. 1167-1181, 2005.

[6] T. G. Huntington, "Evidence for intensification of the global water cycle: review and synthesis," Journal of Hydrology, vol. 319, no. 1-4, pp. 83-95, 2006.

[7] Food and Agriculture Organization, FAO Statistical Yearbook, World Food and Agriculture, 2012.

[8] B. Bates, Z. W. Kundzewicz, S. Wu, and J. Palutikof, "Climate change and water-IPCC technical paper VI," Tech. Rep., Intergovernmental Panel on Climate Change, 2008.

[9] M. Brunetti, M. Maugeri, F. Monti, and T. Nanni, “Temperature and precipitation variability in Italy in the last two centuries from homogenised instrumental time series," International Journal of Climatology, vol. 26, no. 3, pp. 345-381, 2006.

[10] Mediterranean Water Scarcity \& Drought Working Group (MED WS\&D WG), "Mediterranean Water Scarcity and Drought Report: technical report on water scarcity and drought man-agement in the Mediterranean and the Water Framework Directive," Tech. Rep., Europe-an Commission, DG ENV \& Joint Mediterranean EU Water Initiative, 2007.

[11] UNEP/MAP-PLAN BLEU, State of the Environment and Development in the Mediterranean, 2009.

[12] E. Ferragina, “The Water Issue in the Mediterranean," in Environment and Sustainable Development in the Mediterranean, M. Scoullos and E. Ferragina, Eds., pp. 53-77, European Institute of the Mediterranean, Barcelona, Spain, 2010.

[13] L. Perini, "Quando la siccità diventa aridità," ARPA Rivista, vol. 6, 2 pages, 2008. 
[14] E. R. Cook, C. A. Woodhouse, C. M. Eakin, D. H. Meko, and D. W. Stahle, "Long-term aridity changes in the western United States," Science, vol. 306, no. 5698, pp. 1015-1018, 2004.

[15] L. Perini, L. Salvati, T. Ceccarelli, T. Caruso, A. Motisi, and F. P. Marra, Atlante AgroClimatico. Scenari Di Cambiamento Climatico (Con DVD), CRA-CMA, Roma, Italy, 2007.

[16] R. Zucaro and A. Pontrandolfi, Eds., Agricoltura irrigua e scenari di cambiamento climatico Stagione irrigua 2006 nel Centro Nord, Istituto Nazionale di Economia Agraria, 2007.

[17] ISPRA, “Gli indicatori del clima in Italia nel 2008," Rapporto Serie Stato dell'Ambiente n. 12/2009, Anno IV, 2009.

[18] L. Perini, L. Salvati, T. Ceccarelli, S. Sorrenti, and M. Zitti, La Desertificazione in Italia: Processi, Indicatori, Vulnerabilità Del Territorio (Con DVD), Bonanno Editore, 2008.

[19] L. Salvati, "Are Mediterranean coastal regions more exposed to land degradation in recent years?" Journal of Coastal Research, Coastal Education \& Research Foundation, vol. 56, pp. 262-266, 2009.

[20] A. Toreti, F. Desiato, G. Fioravanti, and W. Perconti, "Seasonal temperatures over Italy and their relationship with lowfrequency atmospheric circulation patterns," Climatic Change, vol. 99, no. 1-2, pp. 211-227, 2010.

[21] ISPRA, "Gli indicatori del clima in Italia nel 2009," Rapporto Serie Stato dell'Ambiente n. 09/2010, Anno V, 2010.

[22] UNCCD, "Water scarcity and desertification," UNCCD Thematic factsheet series N. 2, http://www.unccd.int/documents/ Desertificationandwater.pdf, 2010.

[23] N. J. Middleton and D. S. G. Thomas, World Atlas of Desertification, UNEP Edward Arnold, London, UK, 2nd edition, 1997.

[24] V. K. Arora, "The use of the aridity index to assess climate change effect on annual runoff," Journal of Hydrology, vol. 265, no. 1-4, pp. 164-177, 2002.

[25] L. Salvati, M. E. Venezian Scarascia, M. Zitti et al., "The integrated assessment of land degradation," Italian Journal of Agronomy, no. 3, pp. 77-90, 2009.

[26] A. Libertà and A. Girolamo, "Geostatistical analysis of the average temperature fields in North Italy in the period 1961 to 1985," Sciences de la Terre, Serie Informatique, pp. 1-36, 1991.

[27] C. Kosmas, A. Ferrara, H. Briassoulis, and A. Imeson, "Methodology for mapping Environmentally Sensitive Areas (ESAs) to Desertification," in The Medalus Project Mediterranean Desertification and Land Use. Manual on Key Indicators of Desertification and Mapping Environmentally Sensitive Areas to Desertification, C. Kosmas, M. Kirkby, and N. Geeson, Eds., pp. 31-47, European Union 18882, 1999.

[28] M. Cammarrota, G. Bellini et al., Eds., ISTAT Water Resources Assessment and Water Use in Agriculture/ISTAT, ISTAT, Roma, Italy, 2006, Essays, 18/2006.

[29] G. Dal Monte, L. Perini, and F. Thiery, "Studio dell' evapotraspirazione di riferimento nei comprensori irrigui delle regioni Obiettivo 1. Uso integrato delle formule di Hargreaves-Samani e Penman-Monteith," in Atti Del Convegno, 'L'Agrometeorologia Per Il Monitoraggio Dei Consumi Idrici', Sassari, 1999.

[30] L. Salvati and M. Zitti, "Substitutability and weighting of ecological and economic indicators: exploring the importance of various components of a synthetic index," Ecological Economics, vol. 68, no. 4, pp. 1093-1099, 2009.

[31] M. Williams, E. B. Rastetter, G. R. Shaver, J. E. Hobbie, E. Carpino, and B. L. Kwiatkowski, "Primary production of an arctic watershed: an uncertainty analysis," Ecological Applications, vol. 11, no. 6, pp. 1800-1816, 2001.
[32] L. Salvati, T. Ceccarelli, and A. Brunetti, "Geodatabase sul rischio di desertificazione in Italia," CRA-UCEA \& Agrisian, Collana Climagri, vol. 30, 72 pages, 2005.

[33] A. Toreti and F. Desiato, "Temperature trend over Italy from 1961 to 2004," Theoretical and Applied Climatology, vol. 91, no. $1-4,2008$.

[34] A. Toreti, G. Fioravanti, W. Perconti, and F. Desiato, "Annual and seasonal precipitation over italy from 1961 to 2006," International Journal of Climatology, vol. 29, no. 13, pp. 1976-1987, 2009.

[35] T. Nanni and F. Prodi, "Cambiamenti climatici: la situazione in Italia," Energia, vol. 1, pp. 66-71, 2008.

[36] L. Salvati and S. Bajocco, "Land sensitivity to desertification across Italy: past, present, and future," Applied Geography, vol. 31, no. 1, pp. 223-231, 2011.

[37] E. Bou-Zeid and M. El-Fadel, "Climate change and water resources in Lebanon and the Middle East," Journal of Water Resources Planning and Management, vol. 128, no. 5, pp. 343-355, 2002.

[38] Y. Zhang, W. Chen, and J. Cihlar, "A process-based model for quantifying the impact of climate change on permafrost thermal regimes," Journal of Geophysical Research, vol. 108, no. D22, p. 4695, 2003 

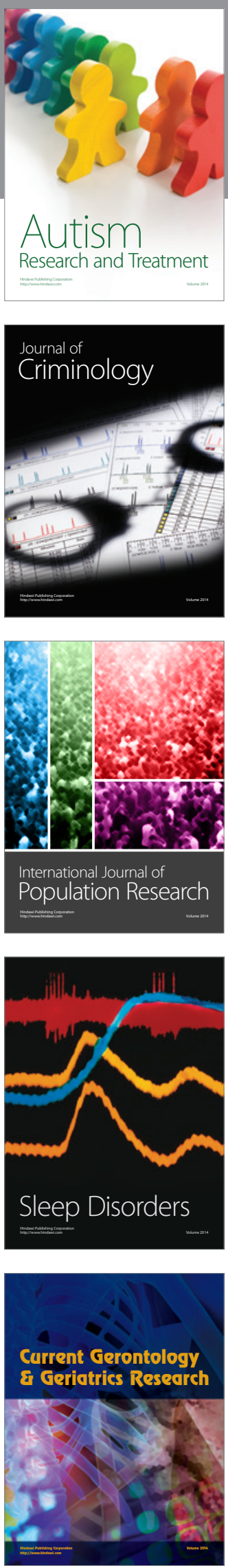
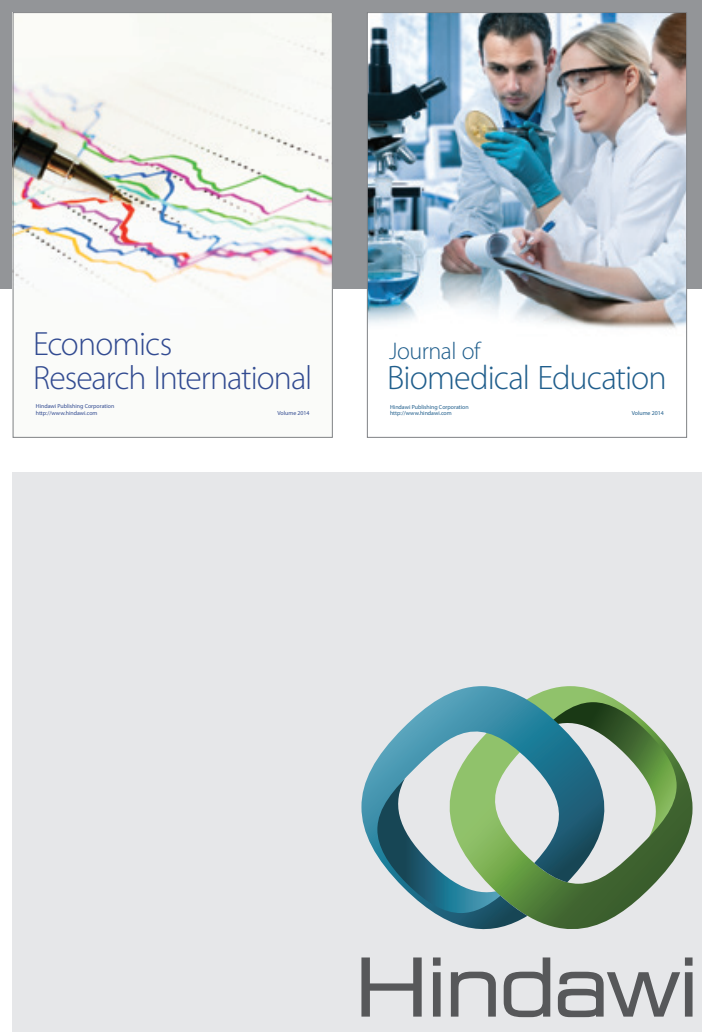

Submit your manuscripts at

http://www.hindawi.com
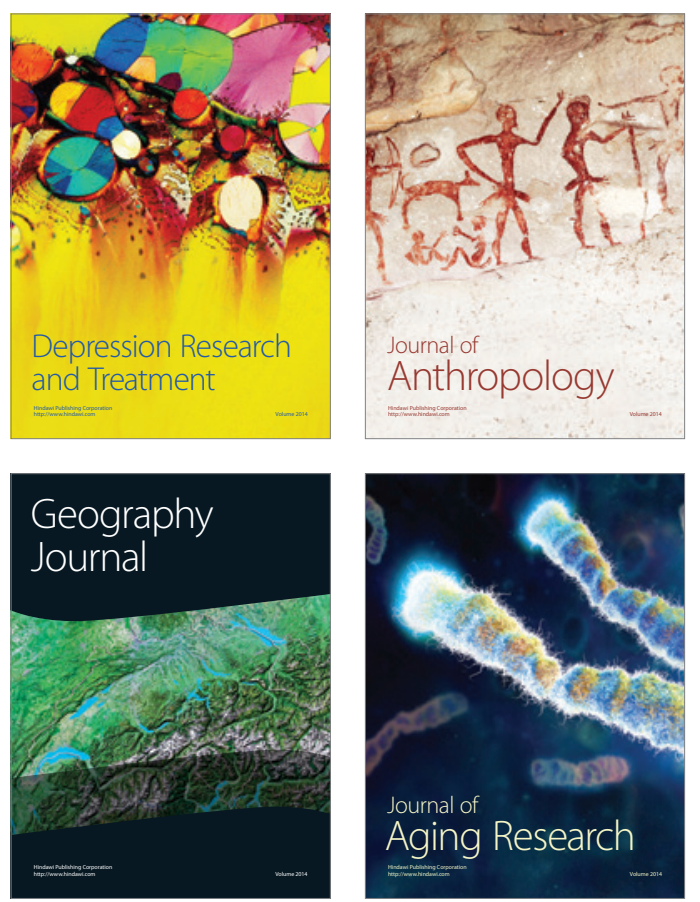
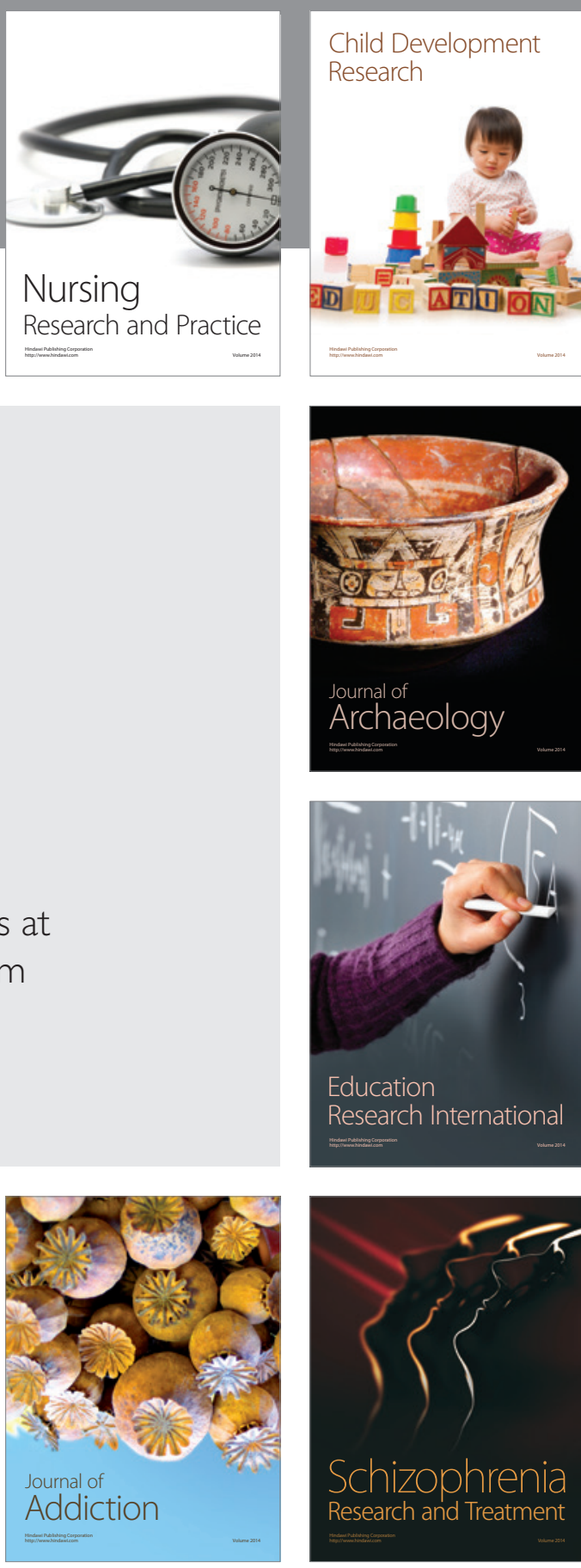

(D)
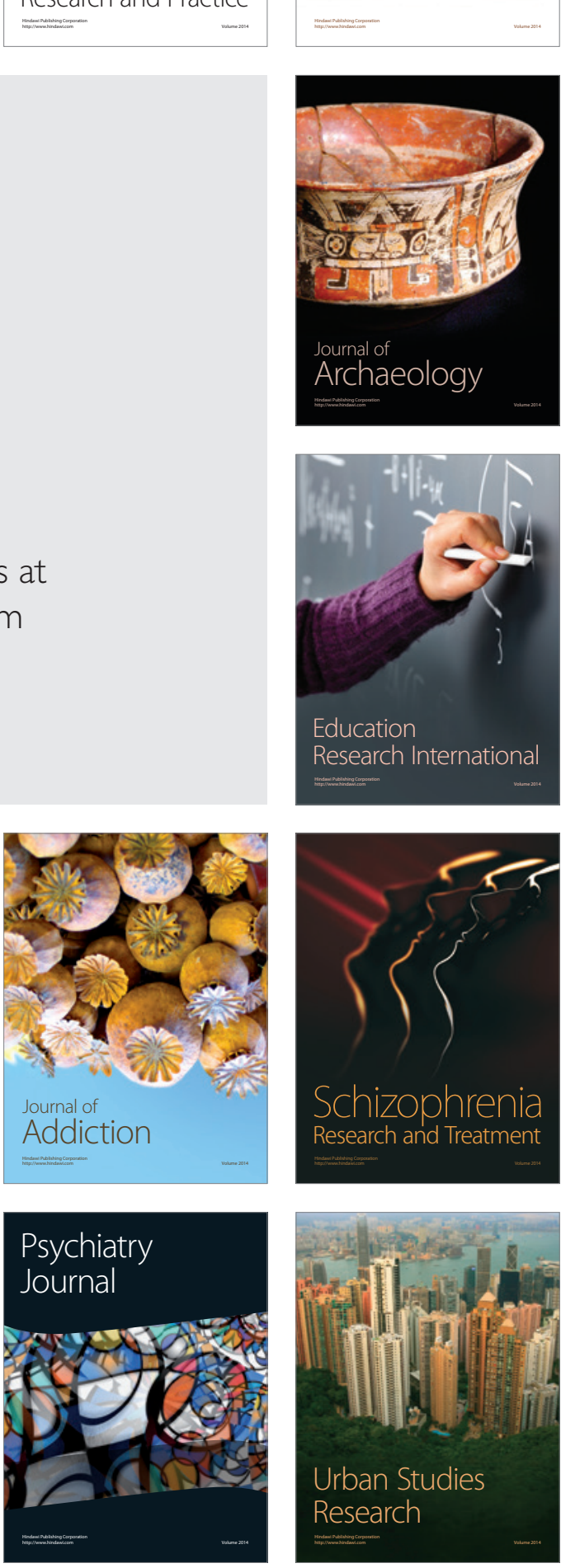